\title{
II Experimental production of naming disorders in normal people
}

The observations recorded in Part I suggest that the breakdown of speech seen in pathological conditions shows some parallels with its acquisition in the developing individual. That it is also related to normal language function in the adult has been suggested by a number of authors. Pick (see Weinstein and Kahn, 1952) noted paraphasic errors in normal subjects in states of inattention, while Kraepelin (see Curran and Schilder, 1935) maintained that sensory aphasia could be compared to the dream language of normal people. Schuell (1950) found that paraphasic errors made by patients could be categorized in the same way as responses to a word association test made by normal people. Weinstein and Kahn (1952) reported that errors similar to those made by aphasic patients were made by subjects performing a reading task under time pressure. Conrad (1954) suggested that the words given by patients with nominal aphasia when asked to name objects could be compared with those given by healthy individuals in front of a tachistoscope when exposure time was insufficient for adequate perception. Flavell and Draguns (1957) noted that when normal subjects were forced to speak continually and at length they tended to perseverate and form 'clangs'. Similarities between the mistakes made by dysphasic patients and those made by subjects while learning a foreign language have also been described by Crewdson (1941). Werner (1956) in a general review of work on aphasia suggested that the disturbance illustrated 'an arrest at a pre-Gestalt stage of the formative process that normally leads to a fully developed form, an end-Gestalt'.

We will describe three studies in which attempts were made to examine the relationship between nominal dysphasia and naming in normal people under more rigidly experimental conditions than those so far reported.

\section{NAMING PERFORMANCE OF ADULTS IN POST-E.C.T. CONFUSIONAL STATE}

Our aim was to discover whether failure to name objects could be demonstrated in confusional states, and if so, whether it followed a comparable pattern to that shown by patients with nominal dysphasia.

PROCEDURE Fifteen English-speaking adults without previous sign of speech disturbance who were undergoing electro-convulsive therapy for depressive illnesses were used in this study. The E.C.T. was modified with scoline in all cases, the anaesthetic used being pentothal (dosage according to body weight) after premedication with atropine. No patient had received more than six treatments in the present series, although several had had previous courses of treatment. Each patient was interviewed individually immediately after treatment. As soon as he was able to give his own name, he was shown the page of pictures (a watch, a comb, a chair, a basket, together with a needle, and an umbrella) used in previous studies and was asked to name each object as it was indicated. He was allowed as long as he liked to look at the picture and to correct any mistakes.

The test was repeated at intervals of five to 10 minutes until the subject had given the correct name to each of the seven objects used in the naming test, namely, watch, comb, basket, hands, teeth, handle, buckle.

RESULTS Table I shows the total number of correct responses made by all subjects on the different objects at the first interview and the average lapse of time after this before the correct name was given to each one. In Table I is also given for comparison the proportion of correct responses to the same items given by 32 dysphasic patients and the average age at which each name was learned by the children whom we interviewed in previous studies. It will be seen that there is a close parallel between the order of difficulty shown by these items in all three groups of subjects (Spearman's coefficient of rank correlation $\sigma=0.9$ ).

Analysis of the errors made by the post-E.C.T. patients shows many similarities to those made by the groups previously studied. For example, the watch was referred to as a 'clock' by three subjects in the present study and the teeth of the comb were given as 'combs' by 11 subjects. Each of these errors has been noted frequently in the previous studies with dysphasic patients and with children.

\section{THE NAMING PERFORMANCE OF ADULTS WHEN DISTRACTED}

The aim was to discover whether distraction or interference influences the naming performance of normal people in the same way as does generalized impairment of mental functioning, and the effect of the relationship of the interference to the name required.

PROCEDURE Thirty English-speaking members of the nursing staff at Littlemore Hospital were used in 
TABLE I

CORRECT RESPONSES IN NAMING OBJECTS BY DYSPHASICS, PATIENTS, AND CHILDREN OF DIFFERENT AGES

Proportion Correct
in 32 Dysphasic
Subjects
Age of Learning by 126 Children
15 Patients after E.C.T.

Proportion Correct at Average Time between Firs First Interview $\quad$ Interview and Name Given (min.)

\begin{tabular}{|c|c|c|c|c|}
\hline Comb & 0.81 & 2 & 0.90 & 1.67 \\
\hline Basket & 0.72 & 4 & 0.65 & $4 \cdot 35$ \\
\hline Watch & 0.74 & 5 & 0.65 & $3 \cdot 35$ \\
\hline Handle & 0.56 & 6 & 0.53 & $4 \cdot 70$ \\
\hline Hands & 0.53 & 8 & 0.33 & $9 \cdot 00$ \\
\hline Teeth & $0 \cdot 28$ & $11+$ & 0.20 & 13.00 \\
\hline Buckle & $0 \cdot 19$ & $11+$ & 0.13 & $16 \cdot 80$ \\
\hline
\end{tabular}

Spearman's coefficient of ranked correlation $\mathbf{P}:-$

Dysphasics/children $P=0.9, T=4.5 \quad$ Dysphasics/E.C.T. patients $P=0.9, T=4 \cdot 5$

$T$ is significant at 0.05 level when greater than 2.365

this investigation. The subjects were interviewed separately. Each one was seated at a table in front of the same picture as those used in the previous investigation. On their heads were placed earphones connected to a Brenell 2-channel recorder. In the right ear, the subjects heard a recorded tape on which the question. 'This is a . . .?' was repeated at two-second intervals. They were instructed to listen to this ear, and after each question to name the object or its part to which the experimenter was pointing. In the other ear the subjects heard either a word frequently given to the object in error by dysphasics, by children, and by foreigners; or a word quite unconnected with the word to be named; or silence.

Owing to the necessity for recording the interference in the left ear, the objects to be named were always presented in the same order, namely, 1 watch, 2 comb, 3 basket, 4 hands, 5 teeth, 6 handle, 7 buckle.

The subjects were divided into three groups, each consisting of five men and five women. Each group was tested under one of the above conditions.

RESULTS Table II shows the proportion of correct responses given by the subjects in groups $\mathrm{a}$ and $\mathrm{b}$ on the seven items individually. It will be seen that the order of difficulty among the items is very similar to that seen in the previous investigations $(P=0.9$, $\mathrm{T}=4 \cdot 5$ ).

Table III shows the proportion of errors on the test as a whole made by each separate group. Both the groups which received interference in the left ear (groups $a$ and $b$ ) made more mistakes in naming than the group receiving no such interference (group c) but the total number of mistakes made was not related to the type of interference received. Table III also shows the number of times in each group that the interference word was given as the response. It will be seen that whereas nearly half the errors made by subjects receiving relevant interference (group a) consisted of the interference word,
TABLE II

PROPORTION OF CORRECT RESPONSES BY SUBJECTS IN GROUPS A AND B

$\begin{array}{ll}\text { Object } & \begin{array}{l}\text { Proportion Correct in Subjects Submitted to Inter- } \\ \text { ference }\end{array}\end{array}$

\begin{tabular}{ll}
\hline Comb & $1 \cdot 0$ \\
Basket & 0.9 \\
Watch & 0.7 \\
Handle & $0 \cdot 8$ \\
Hands & $0 \cdot 8$ \\
Teeth & $0 \cdot 4$ \\
Buckle & 0.5
\end{tabular}

TABLE III

INTERFEROMETER RESULTS

$\begin{array}{lccc} & \begin{array}{l}\text { Relevant }(a) \\ \text { Total failures }\end{array} & \begin{array}{l}\text { Irrelevant }(b) \\ \text { No }\end{array} & \text { None }(c) \\ \text { No response } & \frac{7}{23} & \frac{24}{80} & \frac{20}{80} \\ \text { Total failures } & \frac{10}{23} & \frac{11}{24} & \frac{7}{20} \\ \text { Acceptance } & \text { Total failures } & \frac{0}{24} & -\end{array}$

this was never once the case where the interference was irrelevant in group b.

\section{NAMING PERFORMANCE OF NORMAL ADULTS UNDER TIME-STRESS AND ITS RELATIONSHIP TO FREQUENCY OF WORD USAGE}

Our aim was to investigate the effect of time stress on naming tasks and the relationship between time and word-frequency, and the relationship between word frequency and errors made by patients suffering from nominal dysphasia.

PROCEDURE Two separate investigations were carried out.

In the first simple pen and ink sketches of 25 
different objects were drawn on white cards 6 in. $\times$ 4 in. and were shown one at a time to 35 Englishspeaking members of the nursing and medical staff at Littlemore Hospital. Each object was selected according to the ease with which it could be drawn in recognizable form by amateur artists and the frequency with which its name occurs in everyday language.

For a measure of frequency, reference was made to Teacher's Word Book of 30,000 words (Thorndike and Lorge, 1944) which in the following pages will be referred to as the Thorndike/Lorge frequency. The Teacher's Word Book consists of a list of words each followed by a record of the frequency of occurrence of the word in general taken from the analysis of a wide variety of different samples of literature (column G). AA denotes an occurrence of 100 or over per million words, A denotes 50 to 100 occurrences per million words, while the numbers 1 to 49 denote the number of times under 50 which the word occurs in every million words analysed.

There are several obvious disadvantages to the use of this work as a measure of frequency for the present investigation. The material analysed was entirely written, and there are considerable differences between the frequency of words spoken and those written (Miller, 1951). Many of the samples analysed were from American rather than English sources. The count does not differentiate between the different uses to which a word may be put, for example, the frequency of the word 'hand' does not differentiate between its use to denote the part of the body and its use in other contexts. Despite these objections, the Thorndike/Lorge count, being the only measure of frequency available in the English language today, was relied on as the main source of reference.

The pictures presented to the subjects (Table IV) were chosen to represent a wide range of Thorndike/ Lorge frequencies. Each name was looked up in the Concise Oxford Dictionary and a note was made of the number of different uses listed there, for example, comb has two uses listed, the nominal and the verbal; and the number of different examples quoted of its use in general speech, for example, clock contains the examples of clock-wise, clockwork, clock in. These figures are listed beside the name of each object in Table IV. It will be seen that as expected (Miller, 1951) there is a close parallel between the Thorndike/Lorge frequency and the number of different examples given in the Concise Oxford Dictionary.

Each picture was then drawn again on a new card with a large red arrow pointing to one of its more prominent parts. The parts were again selected to represent a wide range of Thorndike/Lorge frequencies (Table IV).

The 36 subjects were tested individually. Each subject was seated at a table opposite the investigator and was told that cards would be held up and shown to him at the rate of one per second. He was to name the object drawn on the card. If he saw a

TABLE IV

THORNDIKE/LORGE FREQUENCIES

Wholes Oxford Dictionary

\begin{tabular}{lr}
\hline $\begin{array}{l}\text { Object Frequency } \\
\text { (Thorndike/Lorge) }\end{array}$ \\
\hline Rosary & 1 \\
Unicorn & 1 \\
Octopus & 2 \\
Windmill & 11 \\
Violin & 11 \\
Crab & 16 \\
Comb & 19 \\
Needle & $\mathbf{3 4}$ \\
Axe & 35 \\
Pin & 43 \\
Barn & $\mathbf{4 5}$ \\
Angel & $\mathbf{4 7}$ \\
Belt & $\mathbf{4 8}$ \\
Desk & A \\
Wheel & A \\
Clock & A \\
Gun & A \\
Picture & AA \\
Glass & AA \\
House & AA \\
Watch & AA \\
Church & AA \\
Book & AA \\
Flower & AA \\
Fish & AA \\
& \\
&
\end{tabular}

Parts

Object Frequency (Thorndike/Lorge)

$\begin{array}{lrr}\text { Bead (rosary) } & 1 & 20 \\ \text { Tentacle (octopus) } & 3 & 29 \\ \text { Petal (flower) } & 6 & 25 \\ \text { Fin (fish) } & 6 & 10 \\ \text { Buckle (watch) } & 8 & 21 \\ \text { Buckle (belt) } & 8 & 13 \\ \text { Spire (church) } & 11 & 12 \\ \text { Claw (crab) } & 17 & 18 \\ \text { Drawer (desk) } & 20 & 4 \\ \text { Chimney (house) } & 30 & 5 \\ \text { Barrel (gun) } & 32 & 18 \\ \text { Stem (glass) } & 39 & 14 \\ \text { Frame (picture) } & \text { A } & 21 \\ \text { Teeth (comb) } & \text { A } & 20 \\ \text { Handle (axe) } & \text { A } & 10 \\ \text { Horn (unicorn) } & \text { A } & 21 \\ \text { Sail (windmill) } & \text { AA } & 33 \\ \text { Eye (needle) } & \text { AA } & 20 \\ \text { Head (pin) } & \text { AA } & 20 \\ \text { Roof (barn) } & \text { AA } & 20 \\ \text { Spokes (wheel) } & \text { AA } & 17 \\ \text { String (violin) } & \text { AA } & 13 \\ \text { Hands (watch) } & \text { AA } & 10 \\ \text { Page (book) } & \text { AA } & 5 \\ \text { Wing (angel) } & \text { AA } & 4 \\ & & \end{array}$


large red arrow on the card, he was not to name the whole object but the part of it to which the arrow was pointing. The cards were shuffled after each presentation so that the order of presentation varied for each subject. Responses were recorded on a tape recorder.

RESULTS During the course of the study it was soon apparent that a number of the pictures presented primary difficulties of perception in that the subjects were not clear what they were intended to represent. For example, the barn was often referred to as a house, a shed, or a hayrick; the desk was often referred to as a table, and the pin as a nail. The sail of the windmill was seldom distinguished as an isolated part of the total structure.

The total number of errors made to each card is shown on Table IV, where it will be seen that several of the objects used in previous studies (namely the watch, its hands and buckle and the comb and its teeth) have been included. The number of mistakes made on those items shows that they present the same order of difficulty under these conditions as they do in organic dysphasia and in childhood.

No very clear relationship between Thorndike/ Lorge frequency and difficulty can be seen in the centre of the frequency scale (possibly due in part to the perceptual factors mentioned above), but if consideration is given only to the five items at each extreme of Table IV it will be seen that significantly more errors are made on rare words (whether these apply to wholes or parts of objects) than on common ones (Table V).

Analysis of the errors made showed that these could all be classified under a limited number of headings. Those made to the parts were silence, naming of the whole object instead of the part,

TABLE V

THORNDIKE/LORGE FREQUENCIES FOR WHOLE AND PART OBJECTS

\begin{tabular}{|c|c|c|c|c|c|c|c|}
\hline \multicolumn{4}{|c|}{ Whole Objects } & \multicolumn{4}{|c|}{ Part Objects } \\
\hline \multicolumn{2}{|l|}{$\begin{array}{l}\text { Object } \\
\text { Frequency }\end{array}$} & \multirow{2}{*}{$\frac{\text { Right }}{\{108}$} & \multirow{2}{*}{$\begin{array}{l}\text { Wrong } \\
72\end{array}$} & \multicolumn{2}{|l|}{$\begin{array}{l}\text { Object } \\
\text { Frequency }\end{array}$} & \multirow{2}{*}{$\begin{array}{l}\text { Right } \\
75\end{array}$} & \multirow{2}{*}{$\begin{array}{c}\text { Wrong } \\
105\end{array}$} \\
\hline $\begin{array}{l}\text { Rosary } \\
\text { Unicorn } \\
\text { Octopus } \\
\text { Windmill } \\
\text { Violin }\end{array}$ & $\left.\begin{array}{r}1 \\
1 \\
2 \\
11 \\
11\end{array}\right\}$ & & & $\begin{array}{l}\text { Bead } \\
\text { Tentacle } \\
\text { Petal } \\
\text { Fin } \\
\text { Buckle }\end{array}$ & $\left.\begin{array}{l}1 \\
3 \\
6 \\
6 \\
8\end{array}\right\}$ & & \\
\hline $\begin{array}{l}\text { Watch } \\
\text { Church } \\
\text { Book } \\
\text { Flower } \\
\text { Fish }\end{array}$ & $\left.\begin{array}{l}\text { AA } \\
\text { AA } \\
\text { AA } \\
\text { AA } \\
\mathbf{A A}\end{array}\right\}$ & $\{162$ & 18 & $\begin{array}{l}\text { Spokes } \\
\text { String } \\
\text { Hands } \\
\text { Page } \\
\text { Wing }\end{array}$ & $\left.\begin{array}{l}\text { AA } \\
\text { AA } \\
\text { AA } \\
\text { AA } \\
\text { AA }\end{array}\right\}$ & 131 & 49 \\
\hline$x^{2}=32$ & $\mathbf{P}=$ & $=<0.00$ & & $\chi^{2}=20$ & $\mathbf{P}=$ & $=<0.00$ & \\
\hline
\end{tabular}

giving a common but general name instead of one specific to the part indicated. For example, the word leg was frequently given for both the claw of the crab and the tentacle of the octopus. Errors to the whole objects consisted of silence, misidentifications (the barn was called a house, the angel a girl, etc.), naming of one salient detail of the whole instead of the whole object (for example, crucifix for rosary), omission of a salient detail leading to misidentification (for example, horse for unicorn).

In the second experiment we used the two pictures with the lowest Thorndike/Lorge frequency (the unicorn and rosary) used in the previous study, together with two pictures in which a word with high frequency is associated with an unconventionalized pictorial representation (bee, log, frequency 50 to 100 per million), and two in which rare words are associated with stylized pictorial representation (windmill, scarecrow, frequency 1 to 11 per million). These pictures were shown to all those patients referred to us during August and September 1961 who showed clinical evidence of speech disorder due to organic pathology $(\mathrm{N}=10)$. Each subject was interviewed separately and was asked to name each picture as it was shown to him. No time limit was imposed and subjects were allowed as long as they wished to think about their responses. All responses were recorded verbatim.

RESULTS The proportion of correct responses made to each picture by all subjects in this investigation are shown in Table VI. It will be seen that these subjects, like normal people under time stress, have particular difficulty in naming the unicorn and the rosary, but that the common words with unconventionalized pictures (bee and $\log$ ) also present considerably greater difficulty than the uncommon words associated with conventionalized pictures (windmill and scarecrow).

Analysis of the errors made to the rosary and unicorn show a striking similarity between those made by dysphasic patients and those made by normal subjects under time stress (Table VII).

\section{DISCUSSION}

Two demonstrations of the orderliness of language breakdown are reported above. First, a naming test of seven items, when given to dysphasics, children, and normals under experimental conditions, revealed a consistent order of difficuity; secondly, there was great similarity in the type of error made by these groups.

CONSISTENT ORDER OF DIFFICULTY It was noted that this order of difficulty, which was clearly established 
TABLE VI

PROPORTION OF CORRECT RESPONSES TO EACH PICTURE BY ALL SUBJECTS

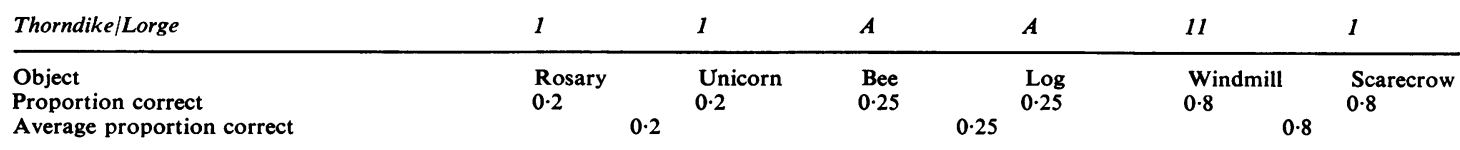

TABLE VII

ANALYSIS OF ERRORS BY DYSPHASICS AND NORMALS

\begin{tabular}{|c|c|c|c|c|c|}
\hline \multirow[t]{2}{*}{ Errors } & \multicolumn{2}{|l|}{ Rosary } & \multirow[t]{2}{*}{ Errors } & \multicolumn{2}{|l|}{ Unicorn } \\
\hline & Instances by Normals & Instances by Dysphasics & & Instances by Normals & Instances by Dysphasics \\
\hline $\begin{array}{l}\text { Chain } \\
\text { Crucifix } \\
\text { Cross } \\
\text { Beads } \\
\text { Necklace } \\
\text { Jewel } \\
\text { Stones } \\
\text { Pallette }\end{array}$ & $\begin{array}{l}5 \\
4 \\
1 \\
3 \\
2 \\
1\end{array}$ & $\begin{array}{l}3 \\
3 \\
1\end{array}$ & $\begin{array}{l}\text { Horse } \\
\text { Lion } \\
\text { Fights with lion }\end{array}$ & 9 & $\begin{array}{l}5 \\
1 \\
1\end{array}$ \\
\hline
\end{tabular}

even though all items could be called 'common objects', was related to the age of acquisition. A plausible explanation of this relationship would be that the dysphasic language breakdown represents a regression and that the first learnt words would be the longest retained. This explanation could also cover the findings under induced nominal aphasia. This explanation, however, is somewhat mystic. What is the nature of the link between age of learning and resistance to pathological and experimental effects? One causal factor influencing both the age of acquisition and resistance to breakdown is probably the frequency with which a word is used and heard in the language. A word is learnt late because it is less often heard and is of less value in communication. Having been learnt late it is then less rehearsed and therefore more likely to be affected by pathological changes and experimentally induced stress. A general relationship is reported above between word frequency and resistance to experimental effects. It must be stressed, however, that word frequency is probably only one of the main factors involved in a naming task. The preliminary investigation summarized in Table VI suggests that the perceptual factors also influence the relationship between words and things, and there is little doubt that perceptual as well as semantic relationships account for the sort of errors that are made when naming tasks are failed.

ERRORS The errors which are made in naming tasks often consist of words which are rarer, in the given context, than the correct word. For example, a subject may call the teeth of the comb 'prongs' and this, in term of frequency, would be a rarer response than the correct word 'teeth'. Superficially this finding refutes any explanation of the ease or difficulty of a naming task in terms of word frequency. But these error words are by no means random and have in fact some communication value within the context in which they are offered. Error words are most often semantically related to the correct word, though occasionally the relationship is perceptual or phonetic.

We have reported the similarity between errors made by normal children and by dysphasic adults (Rochford and Williams, 1962). It may be that the acquisition of a naming vocabulary involves the gradual inhibition of these related errors and the? reinforcement of the single correct name. Naming in normal adults may consist in the selection of the correct word from a pool of alternative responses which are inhibited. These alternative responses would be the words given in error by children and dysphasics. As such, they would be aroused, though preconsciously, as frequently as the single correct word. If the frequency theory were to be pressed it could be said that inhibition is a form of silent rehearsal. There is evidence to suggest that these pool responses or errors do present themselves, preconsciously, in the normal process of naming and indeed in all language tasks, and that one of the disturbances leading to naming errors in dysphasia may be inability to repress or substitute for a pool word once it has been aroused (Bouman and Grünbaum, 1925). If this were so it might be supposed that the greater a pool of possible responses to a given object, the harder would be the selection of a specific name, and conversely that a name which is used in many different contexts or has many different uses would be harder to apply to a given object than one which is specific to one thing. 
Table $\mathrm{V}$ indicates that a general relationship between ease of naming and size of pool is difficult to establish, but further investigation might reveal that where a name is very frequently applied to one common object its application to other less common objects tends to be impeded, and even on occasion denied.

Whatever the many factors involved, it seems unequivocal that the normal correct naming response is the end-product of a complicated pre-conscious selection process, the stages of which can be seen in the performances of children and pathological groups and normals under experimental conditions which interrupt the normal process.

\section{CONCLUSION}

Similarities are reported between the behaviour of pathological and experimental groups, when failing a simple naming task. The pattern of pathological speech disorder is thought to be a function of the normal language process and not of the pathological state as such. What is observed in dysphasia is an exaggeration of tendencies to error which are sucessfully inhibited in normal speech.

\section{SUMMARY}

Three studies are described in which attempts were made to produce paraphasic errors in normal subjects. The conditions studied involved lowered states of awareness following E.C.T., the introduction of time stress, and the introduction of verbal distraction. It was found that all three conditions produced naming difficulties in subjects with other- wise 'normal' speech, and that both the errors and the patterns of breakdown were strikingly similar to those seen in organic dysphasia.

A further experiment was conducted to investigate the effect of frequency of word usage on ease of naming in both normal and dysphasic subjects. Some relationship between these two factors was found but it was suggested that other variables should also be investigated.

We are greatly indebted to the Medical Research Council for the financial grant which has made these studies possible, and to the Institute of Experimental Psychology, Oxford, for the loan of equipment. We would also like to express most grateful thanks to Professor R. C. Oldfield for advice and encouragement, and to all who have allowed us to study the patients under their care, in particular Mr. J. Pennybacker, Dr. Ritchie Russell, and the consultants at Littlemore Hospital.

We would also like to thank the staff of the local schools for their most helpful cooperation.

\section{REFERENCES}

Bouman, L., and Grünbaum, A. A. (1925). Z. ges. Neurol. Psychiat. 96,481 .

Conrad, K. (1954). Brain, 77, 491.

Crewdson, J. (1941). Brit. J. Psychol., 32, 82.

Curran, F. J., and Schilder, P. (1935). J. nerv. ment. Dis., 82, 613.

Flavell, J. H., and Draguns, J. (1957). Psychol. Bull., 54, 197.

Miller, G. A. (1951). Language and Communication. McGraw-Hill, New York.

Rochford, G., and Williams, M. (1962). 25, 222.

Schuell, H. (1950). J. Speech Dis., 15, 291.

Thorndike, E. L., and Lorge, I. (1944). The Teacher's Word Book of 30,000 Words. Bureau of Pub. Teachers College, Columbia Univ., New York.

Werner, H. (1956). J. abnorm. soc. Psychol., 52, 347.

Weinstein, E. A., and Kahn, R. L. (1952). A.M.A. Arch. Neurol. Psychiat., 67, 72. 